If you don't have time to read all these:

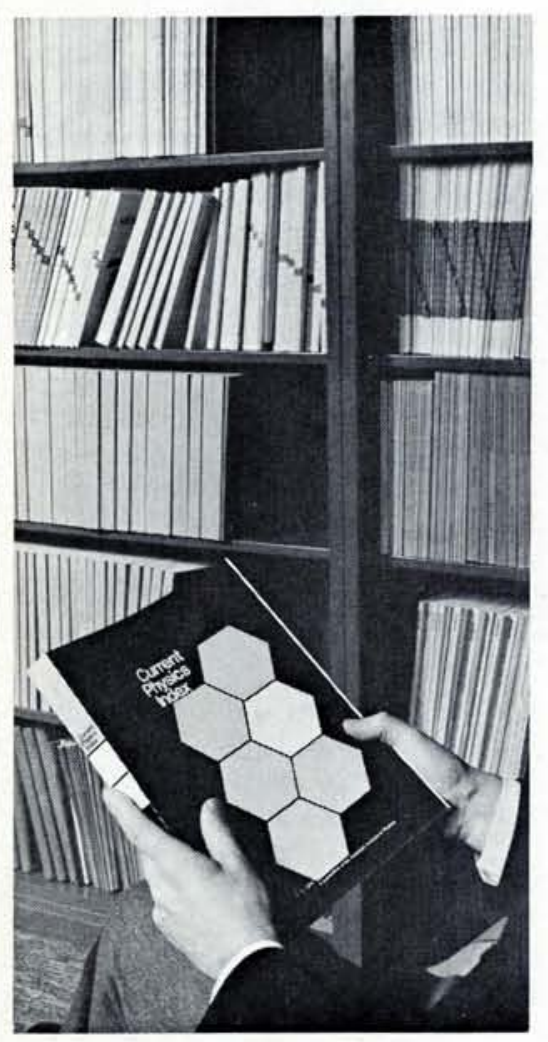

\section{You need this:}

\section{CURRENT \\ PHYSICS INDEX,}

your own private information

retrieval system.

Four times a year, you get an index with over 4,300 abstracts from the journals of the American Institute of Physics and its member societies.

If that sounds like too much to read, you don't have to read it.

Just keep it on your desk and you'll be able to find out immediately who did what, and what he said about it.

The subject and author indexes can tell you more than you ever wanted to know about almost any current subject in physics.

And you also get a 1600 -page Annual Index to sum it all up.

At $\$ 107$ a year, can you afford it? ( $\$ 62$ a year for members of EPS and Affiliated Societies.)

With other indexes at over $\$ 350$ a year, can you afford to be without it?

\section{CURRENT PHYSICS INDEX}

American Institute of Physics

335 East 45th Street

New York, N.Y. 10017

\title{
The JET Project
}

\section{B. J. Green, Garching near Munich}

The status of research in the field of controlled thermonuclear fusion was reviewed in Europhysics News last year (Vol. 5, No 1, Jan. 1974). It was indicated that the two main approaches to isolate the high-temperature reacting plasma from material surroundings are:

1) magnetic confinement, where particularly shaped magnetic fields restrain the highly-ionised working gas (plasma) in a well-defined region of space, so that it can be heated to a degree where the nuclear fusion reactions release large amounts of energy;

2) inertial confinement, where small targets of appropriate material are irradiated by energetic beams (laser or relativistic particles) and sufficient release of fusion energy is achieved before the target material is blown out of the focus region. Here the confinement time is set by the expansion i.e. by target inertia.

The JET (Joint European Torus) project to be described in this article is based on approach No 1, and the magnetic configuration is that of the 'Tokamak', the very successful device developed at the Kurchatov Institute in Moscow. Nearly a decade of painstaking work on this system was necessary before the Tokamak established itself as the most promising configuration to scale up to near reactor size. The 'breakthrough' appeared when it became possible to establish such clean conditions that plasma temperatures could be increased by inducing larger currents $(\sim 100 \mathrm{kA})$ in the toroidal plasma column, and improved values for the plasma energy confinement time ( $10 \mathrm{~ms}$ ) obtained. However, these results were generally accepted only after improved diagnostics verified them. Thus the problem of poor confinement which had plagued experiments until then, had been 'solved'. Although the details of the energy transport were not understood, the ability of the Tokamak to produce and control a plasma with a hitherto-unattained set of parameters, made it the object of an intensive international investigation.

Experimental devices of this type now exist in laboratories not only in the USSR, but also in Australia, The Federal Republic of Germany, France, Italy, Japan, The United Kingdom and the USA. Research with these devices has extended the original work in the USSR and indicated more clearly the potential for development of the system. At the moment plans exist for the next generation of larger Tokamak experiments in Europe, Japan, USA and the USSR. The European contribution is the JET.

\section{The European Scene}

Following the creation of EURATOM, closer co-ordination of the programmes of the fusion laboratories* of the EEC member states became a realistic possibility. Advisory groups in different areas with members from all laboratories were set up to review continually the research situation and discuss the merits of specific programme proposals.

Four separate national Tokamak programmes have been initiated, and are listed in Table 1

\section{TABLE 1}

The National Tokamak Programmes in Europe

\begin{tabular}{lll}
\hline Laboratory & Device & Status \\
\hline UKAEA & CLEO (Tokamak) & completed 1973 \\
& DITE & operation 1975 \\
IPP & Pulsator & 1973: continuing \\
& ASDEX & operation 1978 \\
CEA/Fontenay & TFR & 1973: continuing \\
Grenoble & Petula & operation 1975 \\
CNEN & FT 1 & operation 1975
\end{tabular}

- Belgium: EUR-B (Brussels)

Denmark: EUR-RISø (Risø)

France: EUR-CEA (Fontenay-aux-Roses. Grenoble)

Federal Republic of Germany: EUR-KFA (Jülich),
EUR-IPP (Garching b. München)

Holland: EUR-FOM (Jutphaas)

Italy: EUR-CNEN (Frascati), EUR-CNR United Kingdom: EUR-UKAEA (Culham) 
At the time of writing the TFR is the most powerful operating Tokamak device in the world and has achieved the highest ion temperatures in this type of configuration.

However in 1971 the Tokamak advisory group felt that the time had come to examine the possibility of a combined project, as the increased size of new devices (necessary because the thermonuclear energy output is a volume effect whereas most energy losses do not scale as rapidly) has increased the cost of new experiments to such an extent that a pooling of resources is clearly called for.

A Working Group was set up and several possible approaches were considered. In particular, the aims of such a programme were formulated, certain constraints were set on the design, and it was proposed that a team should be formed to work out the design concept in detail.

In September 1973 the team comprising around 25 scientists and engineers from all the associated partners, assembled at the Culham Laboratory, and the detailed work began in earnest. In order to maintain the closest contact with the partners, scientific workshops and other regular meetings were arranged while the traditionally good contacts with the USSR and USA were maintained.

An initial design proposal has been prepared and it is hoped that the various stages of evaluation, site selection and approval can take place during 1975 so that construction funds can be released at the beginning of 1976. The target date for initial operation is 1980 .

The initial experiments will be carried out in hydrogen at increasing power input levels to investigate the confinement properties. Should these investigations prove to be encouraging, experiments with a deuterium tritium system will be carried out, and thermonuclear reactions and their effects studied.

\section{Aims of the JET Programme}

The aims of the experiment are:

1. To investigate the scaling of plasma confinement characteristics and heating methods over a plasma parameter range extending as far as possible into the thermonuclear region.

2. To study the plasma/wall interaction which may be of a limiting nature. A wall exposed to high energy fluxes (electromagnetic radiation, charged and neutral particles) will suffer damage and will also give off material which enters
Magnetic field Bp produced

by the plasma current $I_{p}$

Coils producing the

toroidal mag. field $B_{T}$

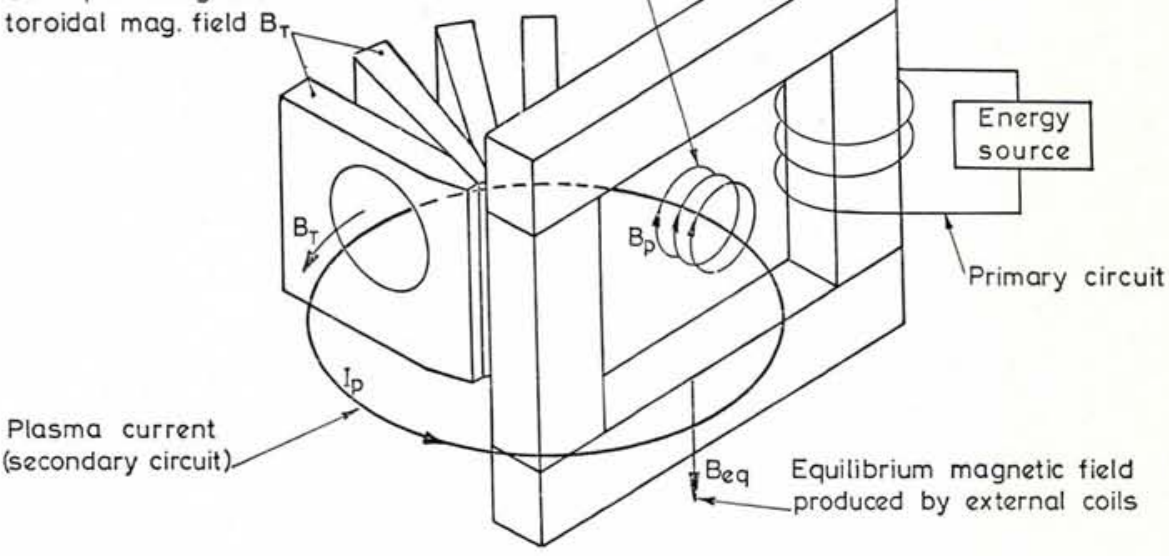

the plasma region. Impurities (i.e. elements other than isotopes of hydrogen) which enter the plasma in this way may cause extremely high radiative losses; bremsstrahlung (for lighter, more easily stripped atoms) and recombination and/ or line radiation (for heavier atoms which are not so easily stripped).

3. To study the effect of $\alpha$-particles from fusion reactions on the plasma. The $\alpha$-particles most easily attainable from fusion are from the reaction

${ }_{1}^{2} \mathrm{D}+{ }_{1}^{3} \mathrm{~T} \rightarrow \mathrm{n}(14.1 \mathrm{MeV})+{ }_{2}^{4} \mathrm{He}(3.5 \mathrm{MeV})$

These may be generated directly in the hot plasma or alternatively by injecting energetic deuterium atoms $(\geq 160 \mathrm{keV})$ into a tritium target plasma.

Should all these aims be fulfilled, then the JET results will provide a firm basis from which a decision can be taken as to whether the system should be developed up to reactor size or not.

\section{Machine Design}

The essential feature of the Tokamak device (see above) is the superposition of two magnetic fields: 1) the large toroidal magnetic field $\mathrm{B}_{\mathrm{T}}$, which is externally produced by a number of magnet coils and which guarantees to a large extent, the macroscopic stability of the plasma; 2) the smaller poloidal field $\mathrm{B}_{p}+\mathrm{B}_{\mathrm{eq}}$, which has two sources, a) the plasma current $\left(I_{p}\right)$ itself giving rise to $\left.B_{p}, b\right)$ external currents giving rise to $B_{\text {eq }}$ which can shape and position the plasma column. It is the poloidal field which is largely responsible for the confinement properties of the device.

The plasma is contained within a vacuum vessel at background gas pressure levels $<10^{-8}$ torr. Initial ionization (pre-ionization) of the working gas can be carried out in many ways.
As soon as the gas is sufficiently conducting, the large Ohmic current is induced by a magnetic circuit with either an air or iron core, the plasma is heated by Ohmic dissipation and the Tokamak equilibrium established.

Auxiliary heating methods are under intensive investigation, because plasma currents above a certain value (related to $\mathrm{Br}_{\mathrm{T}}$ and plasma dimensions) cause instability and subsequent loss of the plasma to the wall. As the current is limited, and plasma resistivity decreases with temperature, the Ohmic heating efficiency also reduces with temperature. Other forms of heating being considered for JET are: the injection of highly energetic neutral atoms, various RF wave heating methods, and magnetic compression.

Some characteristic dimensions of the JET device as it is now conceived are listed in Table 2 below while a

TABLE 2

JET - Characteristic Quantities

Plasma minor radius

(horizontal)

$1.28 \mathrm{~m}$

(vertical)

$1.96 \mathrm{~m}$

Plasma major radius

$2.93 \mathrm{~m}$

Toroidal Magnetic Field at $2.93 \mathrm{~m}$ )

Plasma Current (initial performance)

3 MA

Thickness of the Toroidal Field Coils

$37 \mathrm{~cm}$

Weight of the Vacuum Vessel $80 \mathrm{t}$

Weight of all the Toroidal

Field Coils

$380 t$ 


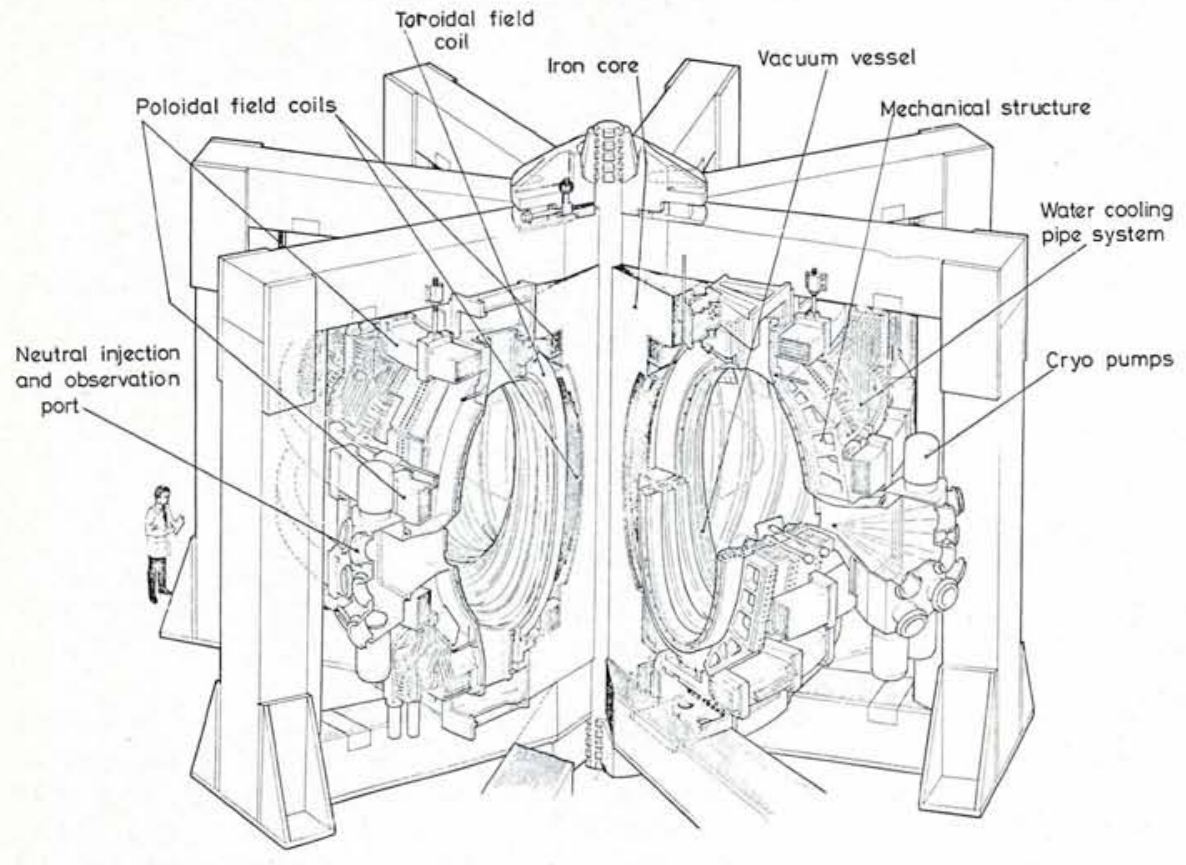

general outline of the engineering design is shown in the figure above.

The 32 toroidal field coils are D-shaped, water-cooled, copper coils which will be able to produce a field of $3 \mathrm{~T}$ at a major radius of $2.9 \mathrm{~m}$, from the vertical axis, for a time of $30 \mathrm{~s}$. The coil shaping is beneficial in terms of mechanical stresses and allows the coil thickness to be reduced.

Since the poloidal field coils have two main functions: 1) to act as a primary winding for the transformer in which the plasma acts as a secondary; 2) to shape and position or compress the plasma column, they are placed outside the toroidal field coils, so avoiding an awkward mechanical linking of the coil systems.

The massive iron core $(\sim 2000 \mathrm{t})$ and the return limbs make up the magnetic flux circuit. A mechanical structure outside the torus, supports the large forces on the toroidal field coils due to the large coil currents and magnetic fields.

Access to the plasma for measuring devices, vacuum pumps and for the injection of highly energetic neutral particles is established by ports (windows) in the vacuum vessel.

The whole is made up of eight identical modules which can be replaced. Should operation with tritium lead to activation of the structure, subsequent operations will have to be performed by remote handling techniques.

\section{JET and Beyond}

There are several features of the JET project which should be discussed but which, for reasons of space, will only be mentioned here.
JET represents only one part of the European CTR programme and other magnetic and inertial confinement systems are being actively studied. The CTR programme itself represents only a small part of an overall energy policy and it should be clear that near-term possible contributions of fusion energy cannot be expected, so that the present energy situation will not be directly affected. However, on a longer time scale, controlled thermonuclear fusion is extremely attractive in terms of fuel availability and reduced radioactivity hazards.

The JET project is a significant step in a fusion technology programme and will require development in the electrotechnical, vacuum and materials research areas. Support from the well-developed field of fission technology is available (e.g. for activation studies, shielding, remote handling etc.) and will be of increasing importance as controlled thermonuclear fusion research develops.

A decision to proceed with a joint European venture in this area will have the practical outcome that many different research groups in CTR and related areas will be brought into closer contact, which can only benefit European physics and the European ideal as a whole.

\section{Edited by \\ Service de Documentation} du CEN-SACLAY et I'Institut National des Sciences et Techniques Nucléaires.

Distributor: I.N.S.T.N., CEN-SACLAY, B.P. No 6 , 91190 Gif-sur-Yvette (France).

Price: 50,00 F. Payment by cheque C.E.A./Trésorerie CEN-SACLAY (other possibilities for French purchasers) chèque postal Trésorerie CEN-SACLAY C.C.P. 9060-84 PARIS.

This volume (407 pages in French or English) contains the proceedings of the Session on Channeling at I.N.S.T.N.-SACLAY on May 27-31, 1974.

\section{Contents :}

General Aspects of Penetration (W. Brandt), Definitions and Generalities (R. Sizmann), Theoretical Aspects of Channeling (R. Ritchie), Canalisation et Localisation d'Impuretés (C. Cohen), Ion Implantation (G. Dearnaley), Décanalisation par les Défauts (Y. Quere), Determination of Nuclear Lifetimes by Use of the Blocking Effect (W. Gibson), Effets Atomiques de la Canalisation (J.-C. Poizat), Effets Directionnels en Emission lonique Secondaire (G. Slodzian), and 15 short contributed papers. 